Gut, 1989, 30, 492-495

\title{
Double blind trial of loperamide for treating acute watery diarrhoea in expatriates in Bangladesh
}

\author{
F P L VAN LOON, M L BENNISH, P SPEELMAN, AND C BUTLER
}

From the International Centre for Diarrhoeal Disease Research, Bangladesh, Departments of Pediatrics and Medicine, New England Medical Center Hospitals, Tufts University School of Medicine, Boston, USA, Unit of Infectious Diseases and Tropical Medicine, Academic Medical Centre Amsterdam, The Netherlands, and Division of Infectious Diseases, Department of Internal Medicine, Texas Tech University Health Sciences Center, Lubbock, Texas, USA.

summary To determine if loperamide is effective and safe in treating watery diarrhoea, we randomly assigned 50 adult expatriates in Bangladesh with more than three unformed stools in the previous 24 hours and illness of less than $\mathbf{7 2}$ hours to receive loperamide or a placebo. On entry into the five day study patients took two capsules (one loperamide capsule $=\mathbf{2} \mathbf{m g}$ ) and one after each unformed stool up to a maximum of eight per day. The groups did not significantly differ in pretreatment features or pathogens identified. Mean number of stools on study day 1 was 2.6 in the loperamide group and 4.0 in the placebo group $(p=0.035)$; on day 2 it was 1.3 versus $3.4(p<0.001)$. Differences in stool frequencies during the final three study days, or proportion of patients with cramps, nausea, or vomiting on any study day, were not significant. No serious side effects occurred in either group. We conclude that loperamide, by decreasing stool frequency during the early part of illness, may have a role in the symptomatic treatment of this self-limiting disease.

Every year about 16 million people travel from industrialised to developing countries, and one third will develop diarrhoea. ${ }^{.}$In one study $20 \%$ of affected travellers were bedridden, and $40 \%$ had to alter their schedules. ${ }^{2}$

This considerable morbidity has prompted efforts to identify symptomatic therapies, which are of four general types. Oral rehydration solutions replace fluid loss but do not influence duration of illness or stool frequency. Some antimicrobial agents decrease the duration of illness and alleviate symptoms. ${ }^{34}$ Adsorbants such as bismuth salts, although effective, are impractical because of the large volumes required. ${ }^{56}$ Lastly the synthetic opiate like antimotility (and possibly antisecretory) agents diphenoxylate and loperamide hydrochloride ${ }^{7}$ are widely used despite few controlled trials ${ }^{\mathrm{\alpha}}$ and concern about their use in patients with shigellosis."

In this study we examined the effectiveness of loperamide compared with placebo in treating watery diarrhoea among expatriates in Bangladesh."

Address for correspondence: F P L. van Loon. MD. ICDDR, B. GPO Box 128. Dhaka-1(X). Bangladesh.

Accepted for publication 30 September 1988.
Methods

PATIENTS

\section{Patients selection and study design}

The International Centre for Diarrhoeal Disease Research, Bangladesh, (ICDDR, B) operates a Travellers' Clinic for expatriates. Patients attending the clinic were eligible for the study if they were 18 years or older, had more than three unformed stools in the previous 24 hours, and had been ill less than 72 hours. Patients were excluded if they had received prior treatment, had visible blood or mucus in their stool, or had a body temperature $\geq 39 \cdot 0^{\circ} \mathrm{C}$.

After written informed consent, patients submitted a fresh faecal specimen for microscopic examination and microbiologic culture. Patients were assigned a sequential study number and corresponding bottles containing the study drug. Treatment had been previously randomised using a random number table. Both loperamide and placebo were prepared as identically appearing capsules, and staff and patients were blinded as to the treatment being given. 
Patients were given two capsules (each loperamide capsule contained $2 \mathrm{mg}$ ) at the start of the study and instructed to take one capsule after each unformed bowel movement, to a maximum of eight capsules per day. They were also provided with sachets of oral rehydration solution. Patients were enrolled in the study between 10 am and 12 noon; the first study day consisted of the 14 to 12 hours until midnight; subsequent study days of the 24 hours from midnight to midnight.

During the five study days patients were requested to keep a diary with the following information: number and character of bowel movements, number of capsules taken, presence of nausea, vomiting, or abdominal cramps, and possible adverse effects of therapy. Patients were also requested to submit additional stool samples for microscopic examination and microbiologic culture on the third and fifth study days.

Patients who had Shigella isolated from their stool were withdrawn from the study. No antimicrobial therapy, or other adjunctive therapy, were provided to patients with other enteropathogens.

\section{LABORATORY METHODS}

A wet mount of faeces was examined microscopically for ova, cysts, and trophozoites of parasites, and the number of red and white blood cells. If cysts or trophozoites were initially absent, the sediment was examined after formol-ether concentration. ${ }^{1}$

Stool was cultured for Salmonella spp, Shigella spp, Vibrio cholerae, Campylobacter, and Escherichia coli using standard methods. ${ }^{12}$ Colonies of $E$ coli were tested for the production of heat labile toxin (LT) by the Chinese hamster ovary cell assay ${ }^{13}$ and for heat stable toxin (ST) by the infant mouse assay. ${ }^{14}$ Rotavirus was diagnosed using an enzymelinked immunosorbent assay without blocking. ${ }^{15}$

\section{STATISTICAL ANALYSIS}

The significance in the difference in means was tested using Student's $t$ test. Differences in mean number of stools was tested using a one-tailed test, on the assumption that loperamide might decrease, but could not increase, stool frequency. All other means were tested using a two-tailed test. Differences in proportions were compared using the $\chi^{2}$ test. All testing was done using Stat-Pac software (Walonick Associates, Minneapolis, Minn, USA).

The study was approved by the Ethical and Research Review Committees of the ICDDR, B.

\section{Results}

Fifty patients from 11 North American and West European countries were enrolled; 27 received
Table 1 Patients' characteristics on admission

\begin{tabular}{lcl}
\hline $\begin{array}{l}\text { Patients } \\
(n)\end{array}$ & $\begin{array}{l}\text { Loperamide } \\
(n=27)\end{array}$ & $\begin{array}{l}\text { Placebo } \\
(n=23)\end{array}$ \\
\hline Men (\% of patients) & 63 & 65 \\
Age (yr)* & $34 \cdot 4$ & $37 \cdot 9$ \\
& $(30 ; 24-65)$ & $(34 ; 23-62)$ \\
Weight (kg)* & $68 \cdot 4$ & $68 \cdot 0$ \\
& $(69 ; 52-91)$ & $(70 ; 47-91)$ \\
Cramps (\%) & 77 & 70 \\
Nausea (\%) & 63 & 57 \\
Vomiting (\%) & 4 & 13 \\
Length of stay in Bangladesh & 145 & 312 \\
(days)* & $(60 ; 3-160)$ & $(100 ; 1-2100)$ \\
Duration of diarrhoea before & $38 \cdot 5$ & $36 \cdot 3$ \\
$\quad$ study (hours)* & $(36 ; 3-72)$ & $(28 ; 3-72)$ \\
Stools in preceding 24 hours* & $7 \cdot 1$ & $6 \cdot 9$ \\
(n) & $(6: 3-24)$ & $(6 ; 3-20)$ \\
Stool WBC/HPF* $\dagger$ & $8 \cdot 8$ & $11 \cdot 2$ \\
& $(6: 1-40)$ & $(8 ; 0-100)$ \\
Stool RBC/HPF* $\ddagger$ & $0 \cdot 7$ & $1 \cdot 2$ \\
& $(0 ; 0-6)$ & $(0 ; 0-6)$ \\
\hline
\end{tabular}

${ }^{*}$ Results given as mean (median; range). $† \mathrm{WBC} / \mathrm{HPF}=$ white blood cells per high power microscopy; $\ddagger \mathrm{RBC} / \mathrm{HPF}=$ red blood cells per high power microscopy. There were no significant differences between treatment groups in any of the characteristics.

loperamide and 23 placebo. Three loperamide treated patients withdrew before the study's completion (two after day 2 , the third after day 4 ); similarly four placebo treated patients withdrew (three after day 2 and the fourth after day 4). For both groups the results before withdrawal were included. Reasons for withdrawal in the loperamide group were lack of improvement in diarrhoea in one patient, severe cramping in a second patient, and infection with Shigella flexneri in a third. Three placebo treated patients withdrew because of a lack of improvement in diarrhoea, and the fourth was infected with Shigella flexneri. One Shigella dysenteriae type 1 infected patient in the loperamide group continued in the study for all five days.

There were no significant differences in characteristics of the groups on admission (Table 1). None of the patients had clinical signs of dehydration. Of the 27 patients in the loperamide group nine submitted three stool samples, 12 two samples, and six one sample; among the 23 placebo patients 15 submitted three samples, six two samples, and two one sample. Enteric pathogens identified from any of these samples are shown in Table 2.

The Figure shows that loperamide patients had significantly fewer stools on study day 1 and 2 than did placebo treated patients. In loperamide treated patients during the five consecutive study days cramps were present in $70 \%, 65 \%, 36 \%$, and $16 \%$ of the patients; in placebo treated patients the corresponding figures were $78 \%, 63 \%, 44 \%, 40 \%$, and 
Table 2 Pathogens identified in any stool collected

\begin{tabular}{lcc}
\hline Organism & $\begin{array}{l}\text { Loperamide } \\
(n=27)\end{array}$ & $\begin{array}{l}\text { Placebo } \\
(n=23)\end{array}$ \\
\hline Campylobacter jejuni & 2 & 4 \\
Ecoli ST & 6 & 2 \\
Ecoli ST and ST & 0 & 1 \\
Ecoli LT & 1 & 1 \\
Shigella spp & 1 & 1 \\
Vibrio spp & 1 & 0 \\
Rotavirus & 1 & 0 \\
Giardia lamblia & 0 & 0 \\
Campylobacter jejuni and rotavirus & 0 & 1 \\
Campylobacter jejuni and Shigella spp & 1 & 0 \\
E coli LT and ST and Giardia lamblia & 1 & 0 \\
No pathogen identified & 13 & 13 \\
\hline
\end{tabular}

$30 \%$. These differences were not significant. Nausea and vomiting occurred less frequently than cramping and did not significantly differ between the groups. Three loperamide treated patients complained of dizziness. Constipation was a complaint of four patients taking loperamide and of three patients taking placebo.

\section{Discussion}

In experimental studies loperamide, a piperidine derivative, slows gut motility by its effects on the intestinal musculature resulting in an increased gut capacity and a delay in intestinal content passage.? Animal studies have suggested that loperamide may also have antisecretory effects. ' The clinical importance of these effects, however, remain unclear. Controlled trials differ as to whether loperamide is useful in the treatment of acute infectious diarrhoea. ${ }^{6 \times 16-20}$ One study in travellers' diarrhoea

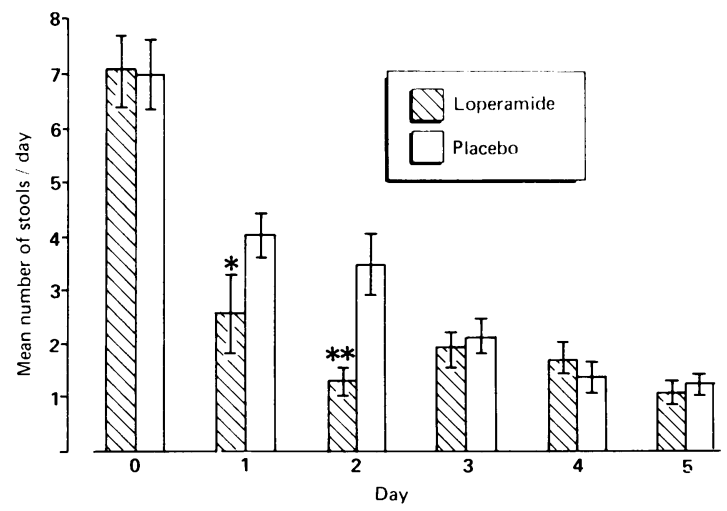

Figure Number of stools per day (mean and standard error of the mean) in patients treated with loperamide or placebo during the 24 hours before the start of the study (day 0 ) and during the five day study period. ${ }^{*} \mathrm{p}=0.035 ;{ }^{* *} \mathrm{p}=<0 \cdot 001$. demonstrated reduction in stool frequency during the first 48 hours of loperamide treatment and in occurrence of cramping. ${ }^{6}$ Another controlled study of loperamide was conducted among Swedish adults with watery diarrhoea half of whom had recently travelled abroad. ${ }^{8}$ During the five day study period the mean number of stools in loperamide treated patients was five, significantly less than in placebo treated patients but not considered of clinical importance. There was no difference in the number of stools during the first day of the study. Compared with patients in our study, however, patients in.that study were less severely ill as determined by stool frequency and had a less acute illness. This perhaps explains the difference in findings between the two studies.

A concern about the use of antimotility agents for infectious diarrhoea is that they may aggravate disease caused by invasive enteropathogens. ${ }^{8}$ Although we excluded patients with clinical symptoms of dysentery, one patient with $S$ dysenteriae type 1 infection, and one patient with simultaneously Shigella flexneri and $C$ jejuni infection, received loperamide. Neither of them developed complications, a finding that is consistent with other studies showing that in adults with infectious watery diarrhoea loperamide does not prolong pathogen excretion or increase severity of illness. ${ }^{67}$ In children with watery diarrhoea, however, complications of loperamide treatment, including shock and enterocolitis, have been reported and we consider it prudent not to provide loperamide treatment to children with acute watery diarrhoea. ${ }^{21} 22$

In conclusion, although watery diarrhoea in adult travellers and expatriates in Bangladesh is usually a selflimiting disease, the reduction in stool frequency that loperamide provides may be beneficial to many of these patients.

The authors thank Isabelle Vesters, RN, for her assistance with patients' care and data collection, $\mathrm{Dr}$ Bogdan Wojtyniak for his assistance in statistical analysis, Drs Roger Eeckels and Andrew Hall for reviewing the manuscript, and Diedie van Dinten for secretarial assistance.

\section{References}

1 Travelers' diarrhea: National institutes of health consensus development conference. Consensus development conference statement. Gorbach SL, Edelman R, eds. Rev Infect Dis 1986; 8: 227-33.

2 MacDonald KL, Cohen ML. Epidemiology of travelers' diarrhea: current perspectives. Rev Infect Dis 1986; 8: 117-21.

3 Merson MH, Morris GK, Sack DA, et al. Travelers' diarrhea in Mexico. A prospective study of physicians and family members attending a congress. $N$ Engl J Med 1976; 294: 1299-305. 
4 Ericsson CD. Johnson PC, DuPont HL. Morgan DR. Bitsura JAN, Javier de la Cabada F. Ciprofloxacin or trimethoprim-sulfamethoxazole as initial therapy for travelers' diarrhea. Ann Intern Med 1987; 106: 216-20.

5 DuPont HL, Sullivan P, Pickering LK, Haynes G, Ackerman PB. Symptomatic treatment of diarrhea with bismuth subsalicylate among students attending a Mexican University. Gastroenterology 1977; 73: 715-8.

6 Johnson PC, Ericsson CD, DuPont HL, Morgan DR, Bitsura JAN. Comparison of loperamide with bismuth subsalicylate for the treatment of acute travelers' diarrhea. JAMA 1986; 255: 757-60.

7 Schiller LR. Santa Ana CA, Morawksi SG, Fordtran JS. Mechanism of the antidiarrheal effect of loperamide. Gastroenterology 1984; 86: 1475-80.

8 Bergstrom $\mathrm{T}$, Alestig $\mathrm{K}$, Thoren $\mathrm{K}$, Trollfors $\mathrm{B}$. Symptomatic treatment of acute infectious diarrhoea: loperamide versus placebo in a double-blind trial. $J$ Infect 1986; 12: 33-8.

9 DuPont HL, Hornick RB. Adverse effect of lomotil therapy in shigellosis. JAMA 1973; 226: 1525-8.

10 Speclman P, Struelens MJ, Sanyal SC, Glass RI. Detection of Campylobacter jejuni and other potential pathogens in travellers' diarrhoea in Bangladesh. Scand J Gastroenterol 1983; 18: 19-32.

11 Allen AVM, Ridley DS. Further observations on formol-ether techniques for faecal parasites. J Clin Pathol 1970; 23: 545-7.

12 Lennett EH, Ballow A, Hausler WJ, Shadowy JH, eds. Manual of clinical microbiology. Washington: American Society for Microbiology, 1985.

13 Guerrant RL, Brunton LL, Schnaitman TC, Rebhum LI. Gilman AG. Cyclic adenosine monophosphate and alteration of Chinese hamster ovary cell morphology: a rapid, sensitive in-vitro assay for the enterotoxins of
Vibrio cholerae and Escherichia coli. Infec Immun 1974; 10: $320-7$.

14 Dean Ag, Ching YC, Williams RG, Harden LB. Test for Escherichia coli enterotoxin using infant mice: application in a study of diarrhea in children in Honolulu. J Infect Dis 1972; 125: 407-11.

15 Yolken RH, Kim HW, Clem T, et al. Enzyme-linked immunosorbent assay (ELISA) for detection of human reovirus-like agent of infantile gastroenteritis. Lancet 1977; ii: 263-6.

16 Owens JR, Broadhead R, Hendrickse RG, Jaswal OP, Gangal RN. Loperamide in the treatment of acute gastroenteritis in early childhood. Report of a two centre, double-blind, controlled clinical trial. Ann Trop Paediatr 1981; 1: 135-41.

17 Kassam AS, Mackour AA, Massoud BZ, Mehanna ZM. Loperamide in acute childhood diarrhoea: a doubleblind controlled trial. J Diarrhoeal Dis Res 1983; 1: 10-6.

18 Diarrhocal Diseases Study Group. Loperamide in acute diarrhoea in childhood: results of a double-blind, placebo controlled multicentre clinical trial. $\mathrm{Br}$ Med $\mathrm{J}$ 1984; 298: 1263-7.

19 Vesikari T. Isolauri E. A comparative trial of cholestyramine and loperamide for acute diarrhoea in infants treated as outpatients. Acta Paediatr Scand 1985; 74: $650-4$.

20 Karrar ZA, Abdulla MS, Moody JB, MacFarlane SB, Al-Bwardy $M$, Hendrickse RG. Loperamide in acute diarrhoca in childhood: results of a double-blind, placebo controlled clinical trial. Ann Trop Paediatr 1987; 7: 122-7.

21 Minton NA, Smith PGD. Loperamide toxicity in a child after a single dose. Br Med J 1987; 294: 1383.

22 Chow CB, Li SH, Lcung NK. Loperamide associated necrotising enterocolitis. Acta Paediatr Scand 1986; 75: 1034-6. 